\title{
Towards falling emissions
}

\author{
Although Europe's new energy plans may be too prescriptive on the means of achieving the goals, \\ they offer the world an encouraging way forward.
}

T he problem with action on climate change is that politically plausible programmes have a tendency to sound too small for the size of the challenge, whereas plans that match the challenge in their scope tend not to sound politically plausible. It is possible, though, that the plans drawn up by the European Union (EU) for a directive on action to reduce the carbon dioxide emissions of the largest economy on Earth, announced on 23 January, have managed to hit the sweet spot in between.

The idea of a ' 2020 ' policy - 20\% less carbon emitted by 2020 , with $20 \%$ of all energy coming from renewable sources by the same date - was first agreed by members of the EU last March. The latest announcement represents the view of how to do this, taken by the European Commission, the EU's executive (see page 504).

Commendably, the proposal sets a clear medium-term goal. There is a tendency, when faced by the daunting challenge of re-engineering the planet's energy infrastructure, to set goals that are ever more ambitious but ever farther off in the future. The commission's policy avoids that, and sends a clear signal to industry about the target to aim for and the means by which Europe will get there: an expansion and tightening of its carbon-trading scheme.

Another welcome aspect is that the proposals are seen by their framers as a minimum. If other major economies sign up for carbon cuts, the EU says it will be willing to step up its own efforts. This is not excessive modesty of goals, but is in part a response to the risk of carbon emissions simply being moved offshore; if European requirements are draconian compared with those elsewhere, then emissions-intensive industries will move away. This would not only mean that jobs and investment would be lost to Europe; it would also, in all likelihood, entrench a laissez-faire attitude to emissions in the economies where those industries ended up.

\section{Fair trade}

Similar considerations are seen in the commission's decision not necessarily to do to energy-intensive industries what it is doing to electricity utilities - forcing them to pay for their carbon credits from $2013 \mathrm{on}$. They are also at play in a willingness to talk, so far in only vague terms, about ways in which these issues might be brought into global trade agreements, perhaps with tariffs on imports from countries that do not put a cost on carbon emissions. These fears of 'carbon leakage' may be overblown, and their popularity with the industries that benefit from such special pleading and traditionally protectionist lobbies definitely calls them into question. But the idea that one can realign the planet's industrial base with no impact on its international trade regime does seem, on the face of it, unlikely. The precedent for giving environmental issues standing at the World Trade Organization has, after all, already been set (albeit on the rather less contentious issue of turtle-friendly nets for prawn fishermen).

A trade war would be a steep and unnecessary price to pay. Far

better for other major economies to follow Europe's lead and set in place similar statutory reductions in emissions. They should not be so keen, though, to emulate other aspects of the plan. Adding a second sonorous ' 20 ' to a plan for 2020 , for example, is hardly a justification for requiring renewable sources to make up $20 \%$ of the total energy mix. Renewable energy is only one low-carbon option: nuclear energy and fossil-fuel energy with carbon capture and storage also need to be pursued. Renewables have their advantages, but a

"The European Union's plan offers a way forward that is neither fantastical nor laggardly."

hard and fast target hardly seems the government intervention that will necessarily best foster the revolution in renewable-energy technologies touted by various visionaries. Such monolithic planning sits poorly with the eclectic entrepreneurialism that is the hallmark of much of the best of the clean-energy sector.

\section{Fuel for thought}

The plan to mandate $10 \%$ use of biofuels in the transportation sector raises similar concerns. Some biofuels are a good thing and some aren't - those derived from crops that are also a source of food are in general best avoided. It is possible that 'second- and third-generation' biofuels, made in new ways from the sorts of biomass best suited to the job, will be a better deal. This area, like many others in the energy sector, will benefit from more research and development funding, both from governments and the private sector. But to assume that the results will be well suited for $10 \%$ of the market just because you say so is foolish.

This over-emphasis on fuel-mix targets reflects a broader problem with the discourse of climate change: it tends to be positioned between public measures on the supply side and individual attempts at conservation on the demand side. But public measures can do a lot for the demand side, too - as indeed the EU is attempting elsewhere - and supply-and-demand measures need to be considered together. Increasing energy efficiency - in the home, in transport, in industry - is an area where governments have a lot to offer. This was appropriately emphasized by Japan's prime minister Yasuo Fukuda at the World Economic Forum in Davos, Switzerland, last week, as a key issue for the G8 summit in Hokkaido in July.

It is important, in the horse-trading that will now ensue between member states as the commission's plans are turned into policy, that their core commitments are not weakened by special pleading. The final policies must be fully verifiable and enforceable. But the new plan offers a way forward that is neither fantastical nor laggardly. It says that if the will is maintained, a major economy can make the crucial historic inflection from a world in which emissions always rise to one in which they fall. They may need to fall faster; but that will be much easier to achieve once they are set to fall in the first place. This is a serious step in that direction, and should be welcomed. 